\title{
Coordination, Learning, and Coups
}

\author{
Andrew T. Little*
}

September 2014

\begin{abstract}
This paper proposes a theory of coups that centers around coordination and learning. The military is modeled as many officers who only want to join a coup if others join as well (i.e., coordination). If the current regime has survived past coup attempts, it is common knowledge that it is relatively strong (i.e., learning). Combining these effects, once the regime survives the first period, officers know that the regime is strong enough that they may refrain from staging a coup - regardless of how dissatisfied they may become with the status quo - under the mutually enforcing expectation that no other officer will rebel. The model has other equilibria where coup attempts can occur after the first period, allowing for more detailed empirical predictions. The analysis highlights several reasons why new regimes are prone to coups, but among regimes surviving the initial turmoil structural factors that would seem to predict coup attempts can have an ambiguous effect. The model also makes novel predictions about how the "initial conditions" of a regime as well as what kinds of changes to payoffs affect the likelihood of coups.
\end{abstract}

${ }^{*}$ Department of Government, Cornell University. andrew.little@cornell.edu 
Following a coup in 1952, Egypt was run by three military men (two of whom were leaders of the coup) for nearly 60 years. When the third of this group, Hosni Mubarrak, resigned in 2011 following a mass popular movement calling for his ouster, many were optimistic about a shift to democratic rule. These hopes did not last long, as his elected (in a relatively free and fair manner) replacement, Muhammed Morsi, barely lasted a year before being forced from office by the military and succeeded by another former officer and coup leader, Abdel Fattah el-Sisi.

While the Egyptian experience is not entirely unique, the heavy involvement of military officers in toppling rulers and running the government has been the exception rather than the rule in recent times. The left panel in figure 1 plots the number of regimes primarily classified as military dictatorships (dashed line) and dictatorships with any military component (e.g., Egypt from 1952-2011) as classified by Geddes, Wright and Frantz (2013) from 1950-2013. ${ }^{1}$ Even with the more inclusive measure, the number of military regimes peaks below 30, and has been under 10 for nearly two decades. The right panel of figure 1 shows that attempts by the military to take control of the state in the same time period follow a similar pattern: the solid line is the number of coup attempts per year (grouped in 5 year intervals) and the dashed line the number of successful coups (data from Powell and Thyne 2011). ${ }^{2}$ After peaking around 10-15 coup attempts per year in the 1960s and 1970s, over the past few decades there have generally been fewer than 5 attempts per year.

Given the military's strong comparative advantage in organization and the ability to inflict violence, it is unlikely that the rarity of coups is driven by the inability of officers, if unified, to topple the government. And while some officers surely prefer the relative safety

\footnotetext{
${ }^{1}$ The less inclusive measure includes regimes categorized as "military", "military-personal", and"indirect military." The more inclusive measure also includes regimes coded as "party-personalmilitary" (e.g., Egypt), and "party-military."

${ }^{2}$ Updated data from beyond 2010 accessed 3/14/2014 from http://www.uky.edu/ clthyn2/coup_ data/home.htm.
} 
Figure 1: Right Panel: Number of military regimes (dashed line) and autocracies with any military component (solid line). Left Panel: Number of successful coups (dashed line) and attempts (solid line line) averaged over five year intervals.
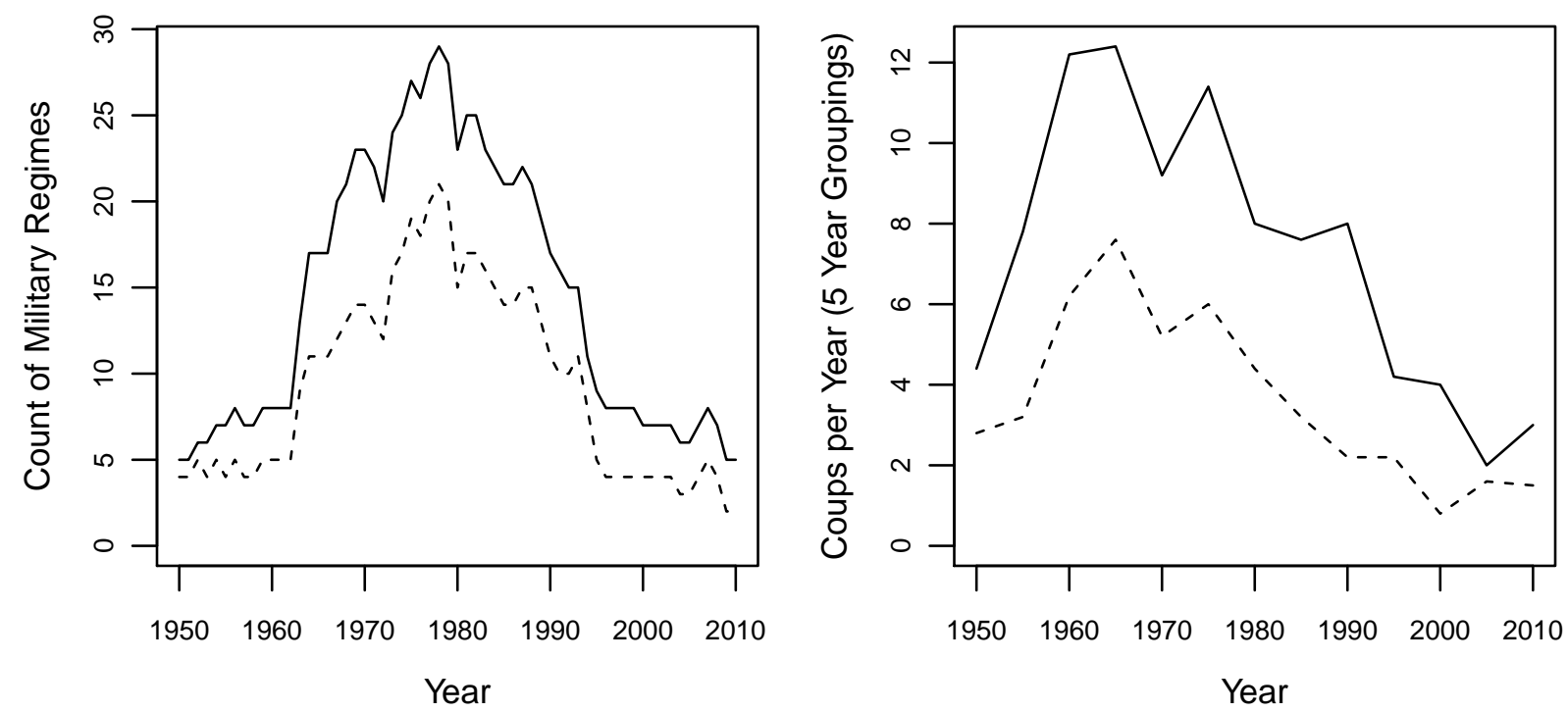

and comfort as salaried agents of the state, common grievances against civilian rulers such as unfavorable policy choices, promotion decisions, or receiving fewer rents than deemed appropriate could be potentially rectified by taking the reigns of government by force.

In this paper I develop a formal model that investigates when officers do (or do not) attempt to exercise this option. I argue that two central forces for understanding when coups are possible and relatively likely are coordination and learning. The coordination aspect of the argument draws on that fact that the military is not a unified actor but comprised of many individuals, and hence "the most important concern for many officers deciding whether to join a coup conspiracy is their assessment of how many others will join" (Geddes, 1999). Existing work showing how this can prevent coups has utilized one-shot complete information coordination games, which always exhibit multiple equilibria: one where a coup occurs and one where there is no coup. As a result these models make no analytic predictions about how a history of coups and economic and political variables such 
as GDP/capita, inequality, and regime type - which have received the bulk of attention in the empirical literature - affect the likelihood of coups.

To address these issues, the model here also includes both uncertainty and time dynamics, and how officers learn about the regime strength over time has important implications for when they are able to coordinate on staging a coup. In particular, the model highlights conditions when learning about the regime strength over time leaves officers unable to coordinate on ousting the regime even if some or many officers would prefer to do so. This allows for the two major contributions of the paper: (1) showing how coordination and learning can lead to an equilibrium with indefinite civilian rule even if the military would generally prefer to take over the government, and (2) deriving conditions under which coups are possible and likely, generating more concrete insights into the empirical literature.

I formalize these ideas with a repeated incomplete information coordination game (Angeletos, Hellwig and Pavan, 2007). When a regime first comes to power, the officers are particularly uncertain about its strength. As a result, a coup always occurs as some officers believe the regime is so weak that it will inevitably fall. If the regime survives to the second period, officers learn an important fact: the regime was strong enough to survive the period one coup. Further, this fact is common knowledge: each individual officer knows that other officers know the regime was strong enough to survive the period one coup, and that the other officers know that he knows this, etc. This leads to the central theoretical result of the paper: there is always an equilibrium where no officers ever launch a coup against a regime after it survives the first period: under the conjecture that other officers use this strategy, there is no chance the regime will fall, making it optimal for each officer to continue supporting the civilian regime. That is, the combination of coordination and common knowledge learning generates a powerful force against attempts to overthrow established civilian regimes, even when "the military" as a unitary actor would be willing 
and able to stage a coup.

However, there can also be equilibria with coup attempts in later periods. Analyzing when this is possible and when coups are likely to be attempted in these equilibria leads to the second major contribution of this paper, which is that it sheds light on several findings and puzzles from the empirical literature on coups. Most notably, numerous hypotheses derived from other theories specify "structural" factors such as economic growth and military spending that should be positively correlated with coups, but the empirical evidence for many of these correlations tends to be weak and inconsistent. In this model, structural factors generally have an ambiguous effect on the likelihood of a coup for a variety of reasons elaborated below, particularly after the initial period of a regime. Second, an extension to the model where the game continues with a new regime after a successful coup makes a prediction which is consistent result that is extremely robust in the empirical record: that coups are much more likely in countries that have experienced coups in the past (e.g., Londregan and Poole 1990). Finally, the model also makes several novel predictions: for example, regimes that survive coups in particularly difficult times send a strong signal of their strength, which renders them less likely to be toppled in later periods.

\section{Extant Work}

This question of how the military can be subjugated to civilian rulers is as old as the study of politics. Plato classically framed this question as as "Who guards the guards," answering that they must be convinced it is improper to stage a mutiny. For the past 50 years explanations of civilian control of the military have arguably not strayed too far from this idea, centering around professionalism and legitimacy as forces against military interventions (Huntington, 1957; Janowitz, 1960). Many have pointed out the circularity in these arguments (e.g., Finer 1962; Feaver 1996; Przeworski 1996): if we define a military 
as professional if it does not interfere with politics, we gain little leverage in explaining variance in military involvement in politics by looking at variance in professionalism. Still, the discussion draws a connection between some features of the model and theories of civilian rule based on legitimacy and professionalism.

These arguments also provide little insight into the fact that not all coups succeed, while, as illustrated by figure 1, roughly half fail. Since the leaders of coups that fail often face nasty fates - losing their jobs, exile, imprisonment, death - this fact should play a key role in any theory of coup initiation. Recent game-theoretic work emphasizes the potential for coups to fail, usually treating the military as a unitary actor that can benefit from taking over office and assuming that such attempts succeed with a (usually exogenous) probability (Geletovic and Sanhueza, 2000; Svolik, 2009, 2013; Besley and Robinson, 2009; Acemoglu, Ticchi and Vindigni, 2010). ${ }^{3}$ In these models, the incumbent regime faces tradeoffs such as making the military strong to defeat outside threats against the fact that this makes the military more able to stage coups (Besley and Robinson, 2009), or making inefficient transfers or policy decisions to make the military less apt to coup (Geletovic and Sanhueza, 2000; Acemoglu, Ticchi and Vindigni, 2010; Svolik, 2013). ${ }^{4}$

More similar to the argument here, many have argued that divisions within the military are important for understanding the likelihood of intervention into politics (e.g., Luttwak, 1968; Decalo, 1976). Several game-theoretic papers have formalized this idea by treating launching a coup as a coordination or collective action problem among officers (Geddes, 1999; Aney and Ko, 2010; Rivero, 2010; Casper and Tyson, 2012; Tyson and Smith, 2013). Geddes (1999) represents divisions in the military with a battle of the sexes game, which I build on by using a more general payoff structure as well as adding incomplete information and an element of time. Rivero (2010) and Aney and Ko (2010) analyze the

\footnotetext{
${ }^{3}$ For a model of why transitions from military to civilian rule, see Debs (2010).

${ }^{4}$ Przeworski (2012) analyzes when the military may want to stage a coup with respect to election timing, but again treats the military as a unitary actor and the probability of success as exogenous.
} 
strategic interaction between factions of the military, and Casper and Tyson (2012), Boix and Svolik (2013), and Tyson and Smith (2013) do so with related coordination games. However, these models primarily focus on different substantive issues and abstract away from the interaction between learning and coordination that drives the central results here.

Treating coups as largely driven by coordination dynamics is consistent with numerous aspects of how they unfold, such as the common strategy of capturing the radio station to announce the coup as fait accompli (e.g., Luttwak, 1968; Bleck and Michelitch, 2013; Singh, 2014). A detailed account of this idea is in Singh (2014), who draws on the game-theoretic literature to argue that whether coups succeed or fail is best understood by viewing them as a coordination game, and presents a wide array of both quantitative and qualitative evidence to support this idea. While we share an emphasis on coordination and how this affects the likelihood of coup success, the main outcome the model here seeks to explain is coup initiation (or lack thereof). Further, by formalizing how coordination and learning interact in a dynamic setting gives more precise predictions about when these effects will prevent (or not prevent) the occurrence of coups.

The model is an application and extension of Angeletos, Hellwig and Pavan (2007), who analyze a repeated incomplete information coordination game outside of any specific political context. The main technical innovation is that I allow the payoffs to change over time, which generates some of the main empirical predictions. Further, in Angeletos, Hellwig and Pavan (2007) the game "ends" following a successful coup, while the extension here considers the long term dynamics where a new regime takes over following a coup. This adds to a growing literature applying incomplete information coordination games - sometimes referred to as global games (Carlsson and Van Damme, 1993; Morris and Shin, 2003) - to political questions such as revolutions and protest (Dewan and Myatt, 2008; Bueno De Mesquita, 2010; Shadmehr and Bernhardt, 2011; Little, 2012; Tyson and Smith, 2013). 
In addition to the primarily theoretical contribution of demonstrating how coordination and learning provide a strong explanation of civilian rule, the model also makes predictions about when coups are likely to occur - and shows why such predictions may be particularly difficult - providing more concrete insights into the empirical literature. Individual studies have identified some correlates of coup attempts and success, such as low income and a history of coups (Londregan and Poole, 1990), instability (Belkin and Schofer, 2003; Casper and Tyson, 2012), whether the current regime is run by the military (Rivero, 2010) and characteristics of the military (Powell, 2012), economic inequality (Svolik, 2013), and economic growth (Kim, 2014). Still, a broad view of cross-national studies of coups is that they have generally found few structural factors about the economy or political characteristics of regimes are consistently and strongly correlated with coup attempts. For example, one factor that has been widely accepted as a strong predictor of coups starting with Londregan and Poole (1990) - income per capita - is only weakly correlated with coups (and not at a conventional significance level) in other recent studies (e.g., Powell, 2012; Svolik, 2013). ${ }^{5}$

The analysis here suggests three reasons why such correlations are difficult to find. First, many of these factors (e.g., natural resource rents) affect both the value of the status quo for the military as well as the value of staging a successful coup, and the effects of these changes on the likelihood of a coup move in opposite directions, making general predictions difficult. Second, the model highlights that any factor that makes a coup easier to stage today also likely made it easier to stage a coup in the past. Finally, any equilibrium with coups after the first period is not unique, so variance in the incidence of coups may be driven more by equilibrium selection than the structural parameters of the model (see Bueno De Mesquita 2010 for an analogous argument about revolutions). That is, if many

\footnotetext{
${ }^{5}$ Singh $(2014$, ch. 3) enumerates 21 hypotheses about factors that some theory predicts would affect the likelihood of coups, only finding robust support for three of them.
} 
militaries play the "no coup" equilibrium, the effect of variables that do unambiguously lead to more coups within the "sometimes coup" equilibrium will be attenuated when both are included in the sample.

The remainder the paper is organized as follows. The next section presents and analyzes the baseline model, followed by an extension where the game continues after a successful coup. The final two sections summarize the empirical implications of the model and conclude.

\section{The Model}

The actors in the model are a unit mass of officers, which are some key subset of the military that may play a pivotal role in the outcome of a coup. The game proceeds over discrete time periods $t=1,2, \ldots$. Officers are indexed by $i$ and time periods by $t$, and subscripts are dropped when this does not create ambiguity. In each period, the officers simultaneously decide whether to participate in a coup. If the proportion of officers staging a coup is greater than the regime strength, denoted $\theta$, then the coup succeeds and the game ends. If the proportion of officers joining a coup - which may be zero - is not sufficiently high, the regime survives and the game proceeds to the next period. The solution concept is Perfect Bayesian Equilibrium, with additional restrictions elaborated below.

\section{Information Structure and Strategies}

At the outset of the game, the officers share a common prior belief about the regime strength $\theta$ that is normally distributed with mean $\mu_{0}$ and precision $\alpha$ (i.e., variance $1 / \alpha$ ). Before the first period, the officers also receive an individual private signal of the regime strength: $s_{i}=\theta+\nu_{i}$, where the $\nu_{i}$ 's are independent normal random variables with mean 
0 and precision $\eta>0$ (again, variance $1 / \eta$ ). ${ }^{6}$ The private signal reflects information that will lead the officers to believe that the regime is ruling successfully or has the support among citizens and elites to withstand a military intervention. It could also reflect local knowledge about the popularity of the regime or about the propensity of other branches of the military to support the government garnered from friends, family, or subordinates.

In each period, all of the officers simultaneously take an action $a_{i t} \in\{0,1\}$, where $a_{i t}=$ 0 indicates that officer $i$ supports the incumbent government in period $t$ and $a_{i}=1$ means officer $i$ participates in a coup (or, for linguistic variety, rebels). Let $A_{t}$ be the proportion of officers staging a coup in period $t$. If this proportion is greater than the regime strength $\left(A_{t}>\theta\right)$, the coup succeeds and the game ends. If the regime is strong enough to survive $\left(A_{t} \leq \theta\right)$, the game proceeds to the next period. The regime strength is constant across periods, though officers' knowledge of this parameter will change; see the discussion for further analysis of this assumption.

Officers do not observe the size of past coups (i.e., $A_{1}, \ldots A_{t-1}$; more on this assumption below), but know that if they are in period $t>1$ the regime must have survived periods $1,2, \ldots t-1$. Further, the sequential nature of the game implies that this fact is common knowledge: that is, officer $i$ knows that officer $j$ knows the regime was strong enough to survive the previous periods, and officer $i$ knows that officer $j$ knows that officer $i$ knows the regime was sufficiently strong to survive, etc. So, the agents private signals received at the beginning of the game are the only endogenous aspects of the history that they can condition on when choosing their actions. ${ }^{7}$

\footnotetext{
${ }^{6}$ In Angeletos, Hellwig and Pavan (2007) the actors receive additional private signals in each period, which is required to get coups in periods after the first since they do not allow the payoffs to change over time as in the model here. Giving citizens more private information as the game proceeds generally makes coups in later periods more feasible, but does not change any of the main conclusions.

${ }^{7}$ Of course the equilibrium strategy will be a function of the current period payoffs as well as other the exogenous parameters. In particular, as demonstrated below, the optimal behavior in round $t$ will indirectly be affected by the past payoffs, as these determine which regimes survive the previous range and hence the belief about $\theta$.
} 
This is admittedly a very reduced form way to model how coups unfold. There is no "plotting", or communication before officers make their decision or whether to coup. In reality some officers will become aware of the potential coup in the early planning stage, while others decide whether to join, oppose, or remain passive as the coup unfolds. For example, Hugo Chávez began creating secret groups within the military that discussed the possibility of a coup in the late 1970s, over a decade before actually staging an unsuccessful coup in 1992 (Marcano and Tyszka, 2007, ch. 3). Further, officers only choose to participate or not, while there are many gradations of actions that officers take during coups: from actively fighting against the participants, to staying neutral with varying degrees of tacit endorsement, to participating as a low-level officer, to planning and leading the execution of the rebellion.

Still, this formulation captures important strategic elements of coups: at all stages, officers choosing whether or not to participate are uncertain about the actions of others who have not yet chosen sides (and if those who have chosen sides will switch). However, the officers will always have some shared beliefs about the strength of the regime, including the fact that it has not yet been overthrown. The model here shows how isolating these coordination and learning effects is sufficient to generate strong and empirically relevant results about the dynamics of coup attempts.

\section{Payoffs}

The officer payoffs in each period are summarized in the following table, where the row corresponds to their participation decision and the column to whether the coup succeeds: ${ }^{8}$

\footnotetext{
${ }^{8}$ Unlike Geddes (1999), the officers here all have the same preferences - though they will have different beliefs about the likelihood of a coup succeeding - and hence identical interests. That is, coordination preventing coups need not arise from some officers preferring civilian control of the military: as emphasized below, civilian control can arise even if all officers prefer to stage a successful coup.
} 


\begin{tabular}{|r|c|c|}
\hline & Coup Fails $\left(A_{t}<\theta\right)$ & Coup Succeeds $\left(A_{t} \geq \theta\right)$ \\
\hline Support Government $\left(a_{i t}=0\right)$ & $v_{0 t}$ & $-k_{0 t}$ \\
\hline Join Coup $\left(a_{i t}=1\right)$ & $-k_{1 t}$ & $v_{1 t}$ \\
\hline
\end{tabular}

The payoff for supporting the government if there is no coup or a failed coup is $v_{0 t}>0$. This parameter represents how much the officers like the status quo, potentially influenced by factors like salaries or whether the government sets policies aligned with the preferences of the military. The payoff to supporting a successful coup is $v_{1 t}>0$. The payoff for joining a failed coup is $-k_{1 t}<0$ and the analogous payoff for supporting the government when the coup succeeds is $-k_{0 t}<0$. All of these terms have a $t$ subscript, indicating that the payoffs may change over time. The payoff for the entire game is a discounted sum of the period utilities; see the appendix for a more formal treatment.

Four aspects of the payoff structure warrant particular attention. First, if the military was modeled as a unitary actor and $\theta \in(0,1]$ and the game only lasted one period, then there would be a unique equilibrium with a coup if and only if the value of joining a successful coup is greater than the value of the status quo $\left(v_{11}>v_{01}\right)$. That is, absent the coordination problem, if the military preferred to stage a successful coup to the status quo, they would do so as it would be guaranteed to succeed. However, by introducing a coordination aspect to the model, officers may refrain from staging coups even if they would drastically prefer to remove the incumbent if it is possible for there to be a mutually reinforcing belief that others will not participate in a coup. Conversely, officers may participate in coups even if they prefer the status quo, consistent with the sentiments of a senior officer in Ghana who supported a coup conspiracy "even though he was a supporter of multi-party democracy, because he felt it was important to support whoever had control of the capital" (Singh, 2014, p. 222). As will be shown below, dis-satisfaction with the status quo will make coups more likely, but is not a necessary condition for a coup to happen. 
Second, adding the coordination element without incomplete information as in Geddes (1999) results in equilibria with and without coups in every period, but generates no analytic predictions about when coups are likely to occur. In this context, the fundamental insight from the global games approach - that by making the realistic assumption of introducing incomplete information we can often get more analytic leverage - allows for richer predictions about when and why coups are possible or likely.

Third, since all officers are atomic, their action will never affect whether the coup succeeds, and hence their action in period $t$ has no affect on their payoffs in later periods. ${ }^{9}$ So, even if the future payoffs were to be drastically different in periods $t+1, t+2, \ldots$ if the coup succeeds or not, the officers' decision in period $t$ is entirely determined by how it affects their payoff in period $t$. A model where officers do consider inter-temporal tradeoffs - perhaps not staging a coup today because it could be easier to do so tomorrow - could generate interesting results (for a related argument see Przeworski 2012), but the payoff structure used here simplifies the analysis by abstracting from these issues.

Further, while the assumption that no individual officers' action can affect the result of the coup does not perfectly apply to all officers, considerations about the likelihood of the coup succeeding are important if not predominant even for actors who may be pivotal. For example, during the failed coup attempt against Mikhail Gorbachev in 1991, the head of the KGB's foreign intelligence arm Leonid Shebarshin ordered his subordinates to not aid the plotters. According to his American counterpart, Shebarshin thought that "had the coup plotters moved resolutely and ruthlessly at the outset ... he would have followed ... orders to deploy the paramilitary team against the holdouts." However, Shebarshin correctly figured the coup would fail "not because he was morally or philosophically against the attempt to oust Gorbachev, but because he read the balance of power correctly" (Bear-

\footnotetext{
${ }^{9}$ See Kricheli, Livne and Magaloni (2011) for a model where citizens do care about the signaling implications of protesting against a regime on future protests, which could plausibly be adapted to the context of coups as well.
} 
den, 2012).

Fourth, a convenient consequence of the payoff structure is that we can capture all of the relevant information from the payoffs with a single parameter. Formally, if an officer assigns a probability $\operatorname{Pr}\left(A_{t} \geq \theta\right)$ to the coup succeeding, then his expected current period payoff is higher when joining the coup - and by the analysis above, he will join - if and only if:

$$
\operatorname{Pr}\left(A_{t} \geq \theta\right) v_{1 t}-\left(1-\operatorname{Pr}\left(A_{t} \geq \theta\right)\right) k_{1 t} \geq-\operatorname{Pr}\left(A_{t} \geq \theta\right) k_{0 t}+\left(1-\operatorname{Pr}\left(A_{t} \geq \theta\right)\right) v_{0 t},
$$

or, rearranging:

$$
\operatorname{Pr}\left(A_{t} \geq \theta\right) \geq \frac{v_{0 t}+k_{1 t}}{v_{0 t}+k_{0 t}+v_{1 t}+k_{1 t}} \equiv q_{t}
$$

That is, $q_{t}$ represents the probability of the coup succeeding that makes an officer indifferent between joining and abstaining from the coup given the payoffs in time $t$. When $q_{t}$ is high - for example, if officers are satisfied with the status quo or the cost of joining a failed coup is high - officers will need to be very confident that the coup will succeed in order to participate. When $q_{t}$ is low - which will occur when the value of staging a successful coup is high or the cost of supporting the government when a coup succeeds is high - officers are more willing to join coups that will not surely succeed. I often refer to conditions favorable to a coup when $q_{t}$ is low and conditions unfavorable to a coup when $q_{t}$ is high.

Assume the payoffs for every period are common knowledge, and are such that $q_{t}$ is always on the interval $(\underline{q}, \bar{q})$, where $0 \leq \underline{q} \leq \bar{q} \leq 1$. Since the officers do not condition their behavior on what they expect will happen in future periods, equilibrium behavior is the same if officers do not learn the period payoffs until before they make their decision in period $t$. 
It is natural to search for equilibria that are monotone in the private signals within each period, in the sense that officers either never coup, always coup, or coup if and only if their private information reveals that the regime is sufficiently weak. I also restrict attention to symmetric equilibria, where all officers use the same threshold strategy. ${ }^{10}$ So, the officer strategy is a sequence of critical thresholds $\left(\hat{s}_{1}, \hat{s}_{2}, \ldots\right)$ such that he joins the coup in period $t$ if and only if $s_{i} \leq \hat{s}_{t}$, where $\hat{s}_{t}=-\infty$ corresponds to the "never coup" strategy and $\hat{s}_{t}=\infty$ to the "always coup" strategy. ${ }^{11}$ A Perfect Bayesian Equilibrium with these restrictions requires that (1) officers form their belief about $\theta$ given Bayes' rule, and (2) given these beliefs it is optimal to join the coup in period $t$ if and only if $s_{i} \leq \hat{s}_{t}$ when the other officers use this strategy as well.

\section{Period 1 Equilibrium}

In a typical infinitely repeated game, the solution to the first period would depend on the continuation value under different outcomes, which depends on the strategies used in later periods. However, the officers are atomic, and hence their behavior in period $t$ has no impact on whether the game ends with a coup or proceeds to the next period. Combining this fact with sequential rationality implies the officers always maximize their current period payoff, and the only aspect of the other officers' strategy that affects this payoff is the period $t$ strategy. So, following Angeletos, Hellwig and Pavan (2007), I first solve for the optimal period 1 strategies, and then characterize the optimal behavior in period $t$ as a function of what happens in periods $1, \ldots, t$.

The first important aspect of the solution is that neither the "always coup" or "never

\footnotetext{
${ }^{10}$ Equilibria of this form always exist, and are the only equilibria that are monotone in all of the private signals. Equilibria not of this form may exist - though in some related models they do not - but would be difficult to characterize with little obvious benefit.

${ }^{11}$ Officers can not condition their strategy on any past behavior, as they do not observe past coup sizes or acquire any new information other than the fact that being in period $t$ means that the regime did not fall in periods $1, \ldots, t-1$. The equilibrium threshold will be a function of the payoffs and the resulting set of regimes that survive up to period $t$.
} 
coup" strategy is used in the first period. There can not be an equilibrium where no officer tries to coup in the first period because some officers always receive extreme enough signals to think that the regime is highly unlikely to survive regardless of the actions of the officers modeled. Intuitively, this corresponds to a situation where an officer is confident that the regime will fall due to an internal struggle, a popular uprising, or a coup from other branches of the military. Similarly, there is no equilibrium where all rebel in the first period as some inevitably get an extreme enough signal to believe that the regime will survive even if all of the officers modeled coup.

The intuition behind the derivation of equilibrium strategy where officers sometimes join the coup in period 1 (and later) is as follows. First, a proposed equilibrium strategy $\hat{s}_{1}$ gives the number of officers that join the coup as a function of the true regime strength; write this as $\operatorname{Pr}\left(s_{i}<\hat{s}_{1} \mid \theta\right)$. Since the private signals are increasing in $\theta$, this probability - and hence the proportion of couping officers - is strictly decreasing in $\theta$. This leads to a critical regime strength $\hat{\theta}_{1}$ such that the regime is toppled by a coup if and only if it is weaker than this threshold: $\theta<\hat{\theta}_{1}$. Given the normal structure of the beliefs about $\theta$, it is then straightforward to calculate the probability that a officer with private signal $s_{i}$ assigns to the the true regime strength is below this critical threshold $\left(\theta<\hat{\theta}_{1}\right)$, which is the probability the coup succeeds. The equilibrium condition is that an officer observing the proposed cutoff threshold $\left(\hat{s}_{1}\right)$ assigns a probability to the coup succeeding exactly equal to $q_{1}$. Officers observing a lower signal think the coup's success is likely enough to make them join. Officers observing higher signals think the regime is stronger and a coup less likely to succeed, and hence support the government.

Formally, an equilibrium strategy for period 1 requires a critical regime strength $\hat{\theta}_{1}$ 
(which corresponds to a strategy $\left.\hat{s}_{1}\right)^{12}$ that solves:

$$
\begin{aligned}
q_{1} & =\operatorname{Pr}(\overbrace{\theta<\hat{\theta}_{1}}^{\text {coup succeeds }} \mid \underbrace{s_{i}=\hat{s}_{1}} ; \overbrace{\hat{s}_{-i}=\hat{s}_{1}}^{\text {threshal for marginal officer }}) \\
& =\Phi\left(\frac{\alpha}{\sqrt{\alpha+\eta}}\left(\hat{\theta}_{1}-\mu_{0}\right)-\frac{\sqrt{\eta}}{\sqrt{\alpha+\eta}} \Phi^{-1}\left(\hat{\theta}_{1}\right)\right) .
\end{aligned}
$$

See the appendix for the derivation of equation 2, which will be illustrated below. As is standard in related models, if the precision of the private signals $(\eta)$ is sufficiently high, there is a unique $\hat{\theta}_{1}$ meeting equation 2 , and hence a unique equilibrium threshold $\hat{s}_{1}$. Later I consider the implications if the model has multiple equilibria, but for now assume the private information is sufficiently precise to guarantee a unique first period equilibrium. So, in the first period there is always a coup, though it may be not be large enough to be detected by an outside observer let alone succeed. The regime will survive if and only if it is sufficiently strong, i.e., $\theta>\hat{\theta}_{1}$. The probability a coup succeeds has the following intuitive properties:

Proposition 1. The probability of a successful coup in the first period is increasing in the value of joining and the cost of opposing a successful coup. The probability of a successful coup is decreasing in the prior mean belief about the regime strength, the cost of joining a failed coup, and the value of the status quo.

All proofs can be found in the appendix.

This result highlights a first reason why structural factors that affect the officer's value of the status quo or for staging a successful coup may have an ambiguous affect on the probability a coup occurs. For example, high natural resource rents likely increase the value of joining a successful coup $v_{1 t}$ (Collier and Hoeffler, 2004), but can also be associated

\footnotetext{
${ }^{12}$ The condition is written with respect to $\hat{\theta}_{1}$ rather than the strategy $\hat{s}_{1}$ because it is not possible to write $\hat{\theta}_{1}$ as an explicit function of $\hat{s}_{1}$.
} 
with a high value of the status quo $\left(v_{0 t}\right)$ if the incumbent regime effectively buys off the military, consistent with the findings in Wright, Frantz and Geddes (2013). Similarly, low spending on soldiers perhaps most directly affects the value of the status quo, but unless spending dramatically changes after a successful coup - which seems plausible but finds little empirical support (e.g., Zuk and Thompson, 1982) - this low level of spending will also be associated with a lower value of staging a successful coup. Formally, structural factors that make $v_{01}$ and $v_{11}$ move in the same direction will have an ambiguous impact on the probability of a coup. Further, this result only applies to the first period of a regime; the relationship between the payoffs and probability of an equilibrium with a coup in later periods will be more even more nuanced.

Despite this ambiguity, it is reassuring that the officers preferences have some impact on the likelihood of a coup occurring and succeeding, which is not the case in complete information formulations (Geddes, 1999; Singh, 2014). In particular, Singh (2014, p. 226) claims that often members of the military do not behave "according to their political preferences, bowing instead to the pressure to coordinate around the presumptive victor." While this true when citizens know whether a coup will prevail, in circumstances where there is uncertainty about whether an attempt will succeed or not, officers preferences do affect their propensity to join or oppose coups in a natural way. In the terminology of Finer (1962), both motive (here, relative payoffs) and opportunity (assessment of the likelihood of success) affect whether the officers attempt a coup.

A surprising characteristic of the first period is that there is always a coup attempt in equilibrium. This is consistent with the intuitive observation that there is often a high level of turmoil at the outset of new regimes, as with Morsi's ouster in Egypt. Such turmoil can occur after the death of a long-ruling dictator dies, or, as elaborated in an extension, a successful coup. More generally, the spike in the number of coups shown in figure 1 may have been driven by the many "new" countries where civilian rule had yet to be established. 
However, as shown in the analysis of subsequent periods, there will not always be coups if the incumbent survives the initial period.

\section{Periods $t \geq 2$}

The main difference between the analysis of the second period (and all subsequent periods) is that it is common knowledge that the regime was strong enough to survive the first period. As a result, the belief about the regime strength is a truncated normal distribution, where the truncation is at $\theta>\hat{\theta}_{1}$. Crucially, this implies that the regime will never fall if none of the officers modeled rebel, as $\theta>\hat{\theta}_{1}>0$. Further, not only does officer $i$ know that the regime will not fall with no coup, officer $i$ knows that officer $j$ knows this, and officer $j$ knows that officer $i$ knows that he knows this, etc.

This observation has powerful implications. In particular, it is common knowledge that if the regime survives period 1, no officer can have a private signal extreme enough to believe the regime will fall no matter what. So, unlike in the first period where some officers always have a dominant strategy to rebel, no officer has a dominant strategy to rebel in period 2. Further, if each officer has a conjecture that no other officers will stage a coup, their best response is to support the government as well. Hence there is always an equilibrium where no officer coups in period 2.

An analogous logic applies to all periods after the first. In any period $t>1$, it is common knowledge that the regime was strong enough to survive the previous periods $\left(\theta>\hat{\theta}_{t-1}>0\right)$, which implies that if no other officers coup it is always optimal to support the government as well. While there may be equilibria with coups as well - as will be analyzed below - the central theoretical result of the paper is that a perpetual lack of coups following the first period is always an equilibrium:

Proposition 2. There is always an equilibrium where no further coups are ever staged against a regime that survives the first period. 
As illustrated in figure 2, the crucial difference between what happens in the first period and subsequent periods arises from the beliefs of officers that receive private information that the regime is extremely weak. In the left panel (period 1), the officer with the extreme signal (grey curve) becomes very confident that $\theta<0$, and hence the regime will inevitably fall. Officers with an extreme enough signal always have a dominant strategy to rebel. In later periods $(t \geq 2)$, the belief about the regime strength is always truncated by the knowledge that the regime survived periods 1 through $t-1$. So, the officer with an extreme signal (grey line) will believe firmly that the regime was barely strong enough to survive up to the current period, but still knows there is no chance that $\theta<0$.

This allows for the construction of an equilibrium with no coups after the first period regardless of how much officers dislike the status quo or would like to overthrow the regime. The argument also holds regardless of how the payoffs change over time: Even if the officers come to dislike the status quo so much that they only require a $1 \%$ chance of the coup succeeding to make be willing to participate, there will be an equilibrium with no coup staged and hence a $0 \%$ chance of success. This provides a plausible explanation for why coups and military rule are quite rare in contemporary politics when officers are often tempted to attempt to take control of the government.

Proposition 2 does not imply that there can be no equilibrium with coups beyond period 1. Even if no officer has a dominant strategy to launch a coup, it may be the case that officers are willing to participate in a coup if they expect others will do so as well. The equilibrium condition for an equilibrium in period $t$ with a positive probability of a coup 
Figure 2: Illustration of the belief about $\theta$ for an officers that receive typical (black curve) and extremely low (grey curve) signals, in period 1 (left panel) and later periods (right panel).
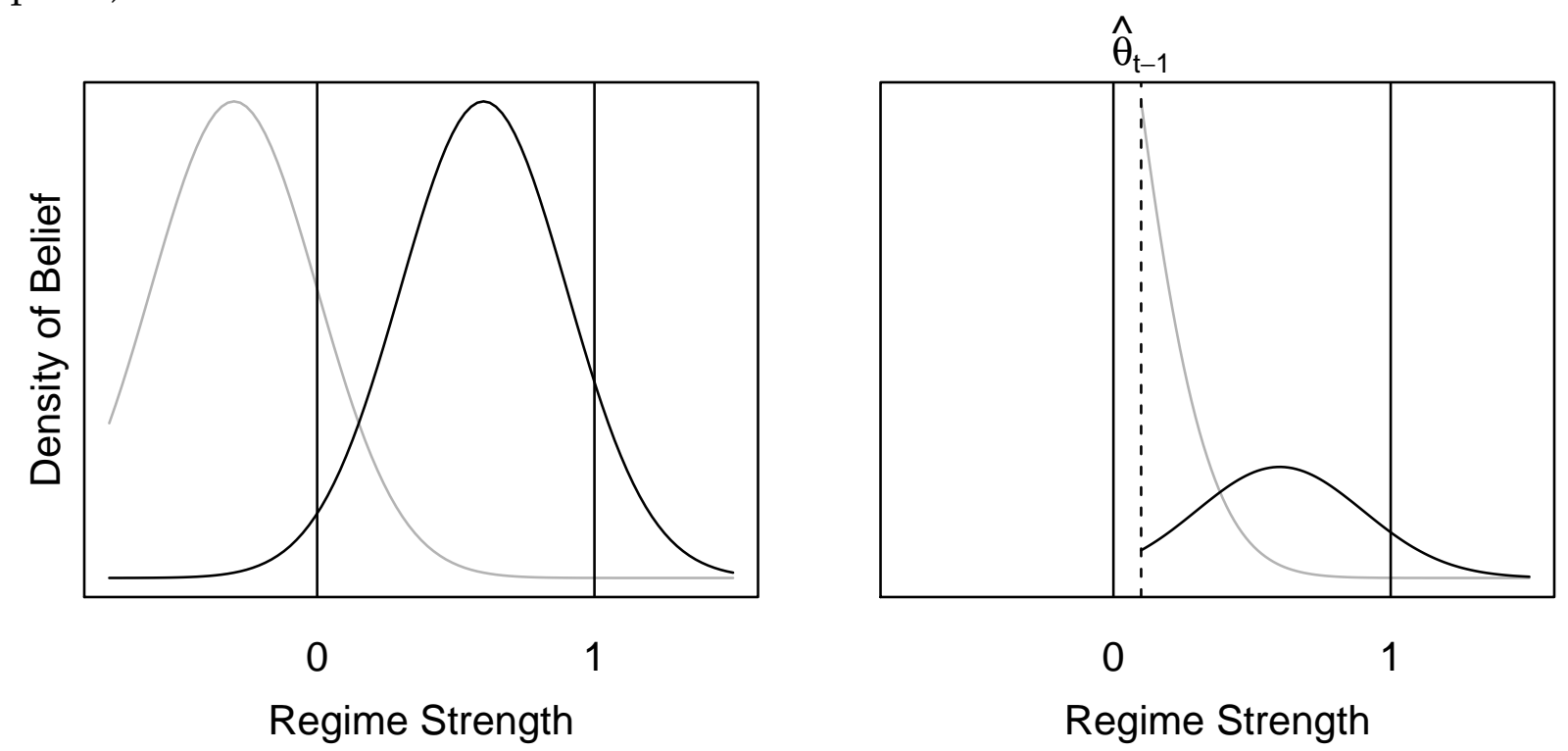

that there exists a $\hat{\theta}_{t}>\hat{\theta}_{t-1}$ that satisfies:

$$
\begin{aligned}
q_{t} & =\operatorname{Pr}(\overbrace{\theta<\hat{\theta}_{t}}^{\text {coup succeeds }} \underbrace{\bar{s}_{i}=\hat{s}_{t}}_{\text {marginal officer signal threshold used by others }} ; \overbrace{\theta \geq \hat{\theta}_{t-1}}^{\text {regime survived to } t} \hat{s}_{\hat{s}_{-i}=\hat{s}_{t}}) \\
& =1-\frac{\Phi\left(\frac{\sqrt{\eta}}{\sqrt{\eta+\alpha}}\left(\Phi^{-1}\left(\hat{\theta}_{t}\right)+\frac{\alpha}{\sqrt{\eta}}\left(\mu_{0}-\hat{\theta}_{t}\right)\right)\right.}{\Phi\left(\frac{\sqrt{\eta}}{\sqrt{\eta+\alpha}}\left(\Phi^{-1}\left(\hat{\theta}_{t}\right)+\frac{\alpha}{\sqrt{\eta}}\left(\mu_{0}-\hat{\theta}_{t}\right)\right)+\sqrt{\eta+\alpha}\left(\hat{\theta}_{t}-\hat{\theta}_{t-1}\right)\right)} \equiv p^{*}\left(\hat{\theta}_{t} ; \hat{\theta}_{t-1}\right)
\end{aligned}
$$

(Again, see the appendix for a derivation of this equation.) As with equation 2, this condition states that an officer receiving the threshold private signal assigns a probability of coup success exactly equal to the probability that makes them indifferent about joining the coup $\left(q_{t}\right)$. The main difference between this equation and equation 2 is the condition in the right-hand side that $\theta \geq \hat{\theta}_{t-1}$, i.e., the probability of the coup succeeding takes into account the fact that the regime was strong enough to survive periods $1, \ldots t-1$. 
The right-hand side of equation is continuous in $\hat{\theta}_{t}$ and is strictly positive for $\hat{\theta}_{t} \in$ $\left(\hat{\theta}_{t-1}, 1\right)$, so one way to characterize the possibility of an equilibrium with a coup is as follows:

Proposition 3. Let $\tilde{q}_{t}=\max _{\theta_{t}} p^{*}\left(\hat{\theta}_{t} ; \hat{\theta}_{t-1}\right)>0$. There is an equilibrium with a coup in period $t$ if and only if $q_{t}<\tilde{q}_{t}$.

A natural interpretation of this result is that there can always be an equilibrium with a coup attempt in period $t$ if the change in the payoffs from the previous period is sufficiently large (and in the direction of making coups easier). Also, recall that if there is no coup attempt in period $t$, then $\hat{\theta}_{t}=\hat{\theta}_{t-1}$. So, a more precise prediction, the implications of which are discussed below, is that there can be a coup attempt if the payoffs change in a manner favorable to coups since the last attempt.

Figure 4 illustrates this result and other aspects of the equilibrium conditions for period 1 (left panel) and subsequent periods (right panel). Both panels show values of $q_{t}$ with horizontal lines and the curve traces out the probability that the marginal officer who observes exactly the threshold private signal assigns to the coup succeeding as a function of the critical regime strength $\hat{\theta}_{t}{ }^{13}$ Lower horizontal lines (i.e., lower $q_{t}$ ) correspond to payoffs that make conditions more favorable to a coup. Intersections of this curve and $q_{t}$ correspond to a critical threshold where the marginal officer assigns a probability of the coup succeeding equal to the indifference probability $q_{t}$, and hence an equilibrium.

In the left panel (period 1), increasing the critical regime strength $\left(\hat{\theta}_{1}\right)$ means that the marginal officer joins the coup when their private information indicates that the regime is stronger, and hence assigns a lower probability of success. ${ }^{14}$ Further, this curve approaches

\footnotetext{
${ }^{13}$ I plot this rather than the officer strategy as $\hat{s}_{t}$ can take on any real value or infinity, while $\hat{\theta}_{t}$ must be on $(0,1)$.

${ }^{14}$ There is a countervailing effect as well: increasing the critical regime threshold corresponds to the other officers being more apt to coup. As discussed extensively elsewhere and in the appendix, when the private information held by the officer is sufficiently precise (as assumed above), the effect of the marginal officer's private signal dominates and hence his belief about the probability of a successful coup is strictly decreasing
} 
Figure 3: Illustration of how the equilibrium condition and how past payoffs affect the probability of a coup in the current period, with $\alpha=1, \mu_{0}=0.5, \eta=1, q_{1}=0.8, q_{1}^{\prime}=.6$, $q_{2}=.35$.

Period 1

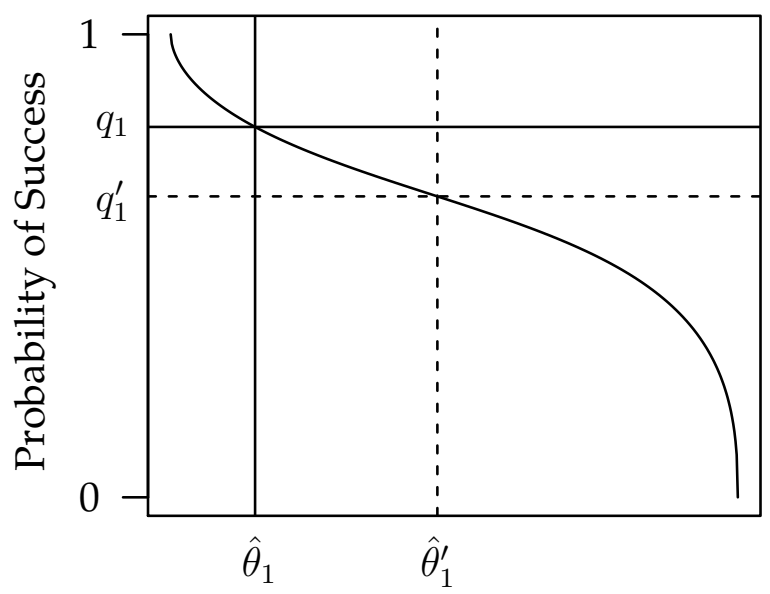

Proposed Survival Threshold
Period 2 (And Later)

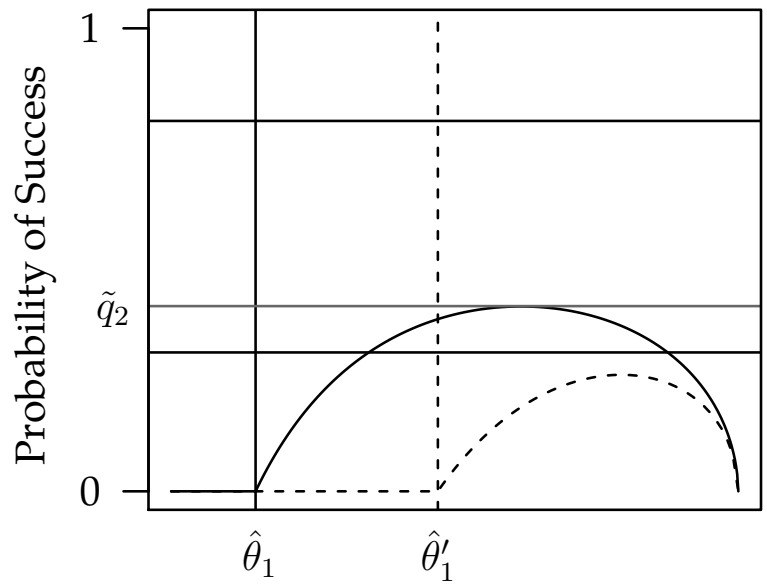

Proposed Survival Threshold

1 as $\hat{\theta}_{1} \rightarrow 0$ and 0 as $\hat{\theta} \rightarrow 1$, ensuring a unique intersection. In this particular case, for the coup favorability given by the solid line $\left(q_{1}\right)$, there is a unique equilibrium where the coup succeeds if and only if $\theta<\hat{\theta}_{1} \approx 0.13$. If conditions are more favorable to a coup ( $q_{1}^{\prime}$, or the dashed line), more regimes fall, illustrating proposition 1.

The right panel plots the equilibrium condition for period 2 (which is only reached if the regime survives the period 1 coup). The solid curve plots the probability the marginal officer assigns to the coup succeeding given the first period payoffs were $q_{1}$, and the dashed line the analogous curve given first period payoffs $q_{1}^{\prime}$. The solid curve peaks at $\tilde{q}_{2}$ which is the maximal level of $q_{2}$ such that there can be a coup in period 2. So, if the conditions remain the same as in period 1, there is no chance for a coup in period 2. However, if the payoffs become sufficiently favorable towards a coup (the lowest horizontal line) in, there in the critical threshold. 
are two intersections, implying a coup attempt becomes possible (proposition 3). ${ }^{15}$

If there is no coup attempt in period 2 , then $\hat{\theta}_{2}=\hat{\theta}_{1}$, and hence the right-hand side of the equilibrium for period 2 is the same as for period 2. In fact, $p^{*}\left(\hat{\theta}_{t} ; \hat{\theta}_{t-1}\right)$ remains unchanged until there is another coup attempt, so the right panel illustrates not just period 2, but every period until there is second attempt (which may be never).

The right panel also demonstrates how the conditions in period 1 affect the possibility of a coup in period 2. In the case where the conditions in period 1 were unfavorable to a coup and the regime has done less to demonstrate its strength (the solid curve), this leads to the potential for a coup in period 2. However, the dashed curve shows that when the conditions were more favorable to a coup in the first period, the regime has proved strong enough that there is no equilibrium with a coup in the second period despite the rapid change in the payoffs associated with the lowest horizontal line. More generally:

Proposition 4. For each time period $t$, let $l(t)$ be the time index of the previous coup attempt. The critical value of $q_{t}$ required for a coup to be possible in period $t$ is decreasing in the coup favorability at the time of the previous attempt (i.e., increasing in $\left.q_{l(t)}\right)$.

The last period with a coup can and often will be the first period of the regime, so one interpretation of proposition 4 is that regimes that survive among initial turmoil may be particularly durable. Smith (2005) makes a related argument about the durability of single party regimes, claiming that "Elites who face and survive the most strenuous fiscal and political crises early on are likely [persist] because they have invested heavily in institution and coalition building." Smith's case study of Indonesia is particularly relevant to this result: the economic crisis at the beginning of Suharto's regime could be interpreted as a low $q_{1}$, meaning there was a substantial truncation about the beliefs about the strength of

\footnotetext{
${ }^{15}$ As discussed in Angeletos, Hellwig and Pavan (2007), the intersection at a lower value of $\hat{\theta}_{t}$ is unstable, though whether this equilibrium is considered or not has no effect on the substantive conclusions relating to the multiplicity, as there is always an equilibrium with no coup at all in later periods.
} 
his regime by surviving this crisis. ${ }^{16}$

Combining propositions 3 and 4 gives a second reason why the effect of structural parameters on the potential for a coup may be ambiguous. Making conditions more favorable for a coup in period $t$ has the expected direct effect of making it easier to stage a coup, but as long as the factors that affect officers' payoffs are serially correlated, countries with favorable conditions for a coup today also had conditions favorable towards coups in the past. This generates an effect in the opposite direction, as those who survived when conditions were favorable for a coup in the past do more to demonstrate their strength, making coups harder to stage today.

Finally, proposition 3 implies that if the payoffs can fluctuate with a wide enough range - there are multiple equilibria in the model. In one equilibrium, there is never a coup after the first period, while in the other equilibria coups can occur in later periods (potentially in any period). This provides a yet another reason why it may be difficult to predict coups with structural parameters: since societies with identical payoffs could play different equilibria with different prevalence of coups, variance in the incidence of coups can be at least partially driven by equilibrium selection rather than differences in the incentives faced by officers.

\section{Trajectories}

This section presents an extension to the model analyzed above by allowing the game to continue after a coup succeeds. After a successful coup, a new regime begins, which could be interpreted as a military regime led by the previous coup plotters, or as a civilian regime

\footnotetext{
${ }^{16}$ The details of Smith's argument are not the same as the one made here, as it focuses more on the strategic decisions made early in regimes that face crises as good investments for later survival. Still, there is no reason why initial turmoil can not contribute to durability for both strategic choices and learning.
} 
which is given power by the coup purveyors. ${ }^{17}$ The most technically straightforward way to define the game is that the actors constituting the officers remains constant (i.e., the coup plotters install a new government and then return to the barracks), but equivalent results could be derived if the military indeed stays in power. The officers period payoffs are the same as above. The payoffs for the entire game are different since it does not end if a coup occurs, but since the officers are atomic they still always maximize their current period payoff. ${ }^{18}$

Call the strength of the first regime $\theta^{1}$, and the strength of subsequent regimes $\theta^{2}, \theta^{3}, \ldots$, or, generically $\theta^{r}$. Extending the definition above, if regime $r$ is in power at time $t$, they survive to time $t+1$ if and only if the size of the potential coup in period $t$ is $A_{t}<\theta^{r}$. If not, the coup succeeds, and regime $r+1$ begins at time $t+1$. When this occurs call time period $t+1$ the initial period for regime $r+1$.

Assume each regime strength $\theta^{r}$ is given by $\theta^{r}=\bar{\theta}+\epsilon^{r}$ where $\epsilon^{r}$ is normally distributed with mean 0 and precision $\tau_{\epsilon}$. The $\bar{\theta}$ parameter represents the average regime strength, and the $\epsilon^{r}$ term captures whether regime $r$ is stronger or weaker than average. Assume the prior belief on $\bar{\theta}$ is normally distributed with mean $\mu^{1}$ and precision $\tau_{0}$. That is, officers are uncertain about how strong a typical regime is, and hence will learn about this average strength based if they experience multiple regimes. However, even if the officers become certain about the average regime strength $(\bar{\theta})$, they will always be uncertain about the strength of the current regime because of the $\epsilon^{r}$ term.

Further, assume that while officers do not observe the size of failed coups as before,

\footnotetext{
${ }^{17}$ Goemans and Marinov (2013) find that in recent years, even if coup purveyors attempt to stay in power, they at least hold an election

${ }^{18}$ This can lead to some unusual welfare implications if $v_{1 t}$ is sometimes or always greater than $v_{0 t}$, in which case the officers first best outcome is to have a (successful) coup in every period. A more realistic model would consider the future fate of those staging successful coups as endogenous, where the payoff for staging a successful coup today depends on whether there is a counter-coup in the future. Still, the model here is sufficient to generate empirically relevant results about the instability of new regimes that would not obviously be overturned in this more complex setting.
} 
they do observe the size of successful coups, and as a result know the strength of all past regimes. ${ }^{19}$ This information structure implies that in the initial period of any regime, the belief about its strength is normal as well. In particular:

Lemma 5. The prior belief about the strength of regime $r \geq 2$ in its initial period is normally distributed with mean and precision:

$$
\mu^{r} \equiv \frac{\sum_{j=1}^{r-1} \tau_{\epsilon} \theta^{j}+\tau_{0} \mu^{1}}{\tau_{0}+(r-1) \tau_{\epsilon}} \quad \text { and } \quad \alpha^{r} \equiv \frac{\tau_{0}+r \tau_{\epsilon}}{\tau_{\epsilon}\left(\tau_{0}+(r-1) \tau_{\epsilon}\right)}
$$

Prior to the initial period of each regime, the officers all observe a private signal of the new regime's strength $s_{i}^{r}=\theta+\nu_{i}^{r}$, where the $\nu_{i}^{r}$ terms are independent normal random variables with mean 0 and precision $\eta$.

Given the normal structure of these beliefs, the analysis of the game beginning after a coup is identical to the game analyzed above with a different prior belief about the regime strength and a shift in the time index.

So, modified versions of all of the results above hold for the game beginning at regime $r$. For example, there is always an equilibrium where the first $r-1$ regimes fall with some positive probability, and then regime $r$ survives indefinitely provided they are not toppled in their initial period. The analogous result about the initial period of each regime is:

Proposition 6. There is always a coup in the initial period of a regime, with the comparative statics derived in proposition 1. The probability that this coup succeeds is also increasing in the size of the previous $\operatorname{coup}(\mathrm{s})$.

New regimes are unstable and prone to coups for two reasons. First, as identified in the baseline model, they have yet to demonstrate their ability to stay in office, and hence some officers will always believe they are sure to fall and will coup. Second, the fact that

\footnotetext{
${ }^{19}$ As with the rest of the information structure, this assumption is designed to retain the (truncated) normal structure of the officer's beliefs.
} 
the previous regime was ousted by a coup generally causes the officers to believe that the average regime is easier to topple, and hence lowers the belief about the current regime as well. ${ }^{20}$ This is consistent with the strong - and, arguably, most robust - empirical finding that past successful coups are a strong predictor of future coups (e.g., Londregan and Poole 1990; Belkin and Schofer 2003).

However, as shown in proposition 4, regimes that survive particularly difficult initial periods (and later coups) send a particularly strong signal of their strength, potentially becoming resistant if not immune to later coups. For example, Syria had 8 successful military coups between 1950 and 1970 before Hafez al-Assad ousted rival Salah Al-Jadid and ruled until his death in 2000. After surviving early on in an environment that unseated many other leaders, the durability of Assad's regime was driven by the fact that he "weathered numerous storms and survived countless crises, with the result that his subjects and his colleagues in power have come to see him as a strategist of incomparable gifts" (Seale, 1991).

\section{Discussion}

Before concluding I briefly discuss the robustness of the results to some of the more objectionable assumptions and summarize the implications for empirical work on coups.

\section{Robustness}

The choice to allow the payoffs to change over time but keep the regime strength constant is not primarily driven by substantive concerns but the fact that doing so generates a relatively tractable model. As is typical in formal models, there are many equally defendable choices regarding what parameters of the model change over time as well as what the

\footnotetext{
${ }^{20}$ This is not inevitably true: if $\theta^{r-1}>\mu^{r-1}$ but the regime is still ousted by a coup, the audience will believe the average regimes strength is higher than before.
} 
actors are uncertain about.

The sharpest theoretical results of the paper (e.g., proposition 2) rely on the fact that surviving a coup removes the possibility that the regime will fall on its own, always allowing for an equilibrium with no coups after the first period. This fact is certainly objectionable. For example, if the regime strength can change in a sufficiently volatile manner - as in one of the extensions analyzed in Angeletos, Hellwig and Pavan (2007) - then the officers can never rule out the possibility that it will fall on its own and there will be some attack in each period. Still, a weaker property that the officers learn about the regime strength from what (if any) coups the regimes has survived in the past likely holds in a wide range of models with different specifications of the uncertainty and changes over time. So, even if we can not always construct an equilibrium where civilian rule lasts indefinitely after the first period, civilian regimes surviving over time will still lead to common knowledge learning about their strength that makes staging a coup more difficult if not necessarily impossible.

Another objectionable assumption is that officers do not observe the size of past coups. Imperfectly observing the size of previous coups complicates the analysis, but does not change the possibility of constructing an equilibrium with no coups after the initial period (again, see Angeletos, Hellwig and Pavan 2007). ${ }^{21}$ In addition to verisimilitude, a nice aspect of allowing partially observed coups is that unsuccessful coups can "snowball." That is, other than the model here where failed coups tend to be followed by long phases with no coups, observing a nearly successful coup can trigger another coup right away.

\footnotetext{
${ }^{21}$ If the size of the period 1 coup is perfectly observed, the officers perfectly learn $\theta=\Phi^{-1}\left(A_{1}\right)$, resulting in a complete information game.
} 


\section{Implications for Empirical Work}

As discussed throughout the analysis, the model highlights various reasons why predicting coups with typical political and economic variables may be hard. Here I elaborate on several implications of the model for the empirical study of coups

As highlighted by proposition 1, it is important for empirical analysts to think about whether political and economic variables affect the value of the status quo for officers, the value of taking control of the government, or both. Determining whether a factor like natural resource rents affects one of these values more than the other is not something that can be formally tested, but when combined with substantive judgement the results here may provide additional insight into the conditions under which structural conditions can predict coups.

Next, proposition 3 suggests that changes in economic and political variables may have a more clear effect on the likelihood of coups than absolute levels. While some empirical work has found little correlation between economic growth and coups (Rivero, 2010; Powell, 2012; Goemans and Marinov, 2013), Kim (2014) finds that when transitory shocks to growth caused by weather (though not more permanent shocks measured by changes to oil prices) are positively associated with coups. This finding is consistent with the theoretical predictions: to cast Kim's argument in the language used here, looking at changes in GDP avoids the problem of past and current payoffs moving in opposite directions, and transitory shocks to weather plausibly lower the value of the status quo in period $t$ but not the value of staging a successful coup. On the other hand, changes to oil prices are more likely to lower the value of staging a successful coup, providing an explanation for the non-finding in changes to GDP induced by through this channel.

In addition, proposition 3 makes a more precise prediction that may be less sensitive to noisy data: the most clear predictor for whether coups are feasible could be the change in $q_{t}$ - which again could be proxied by typical variables such as income per capita, natural 
resource rents, or military spending - since the last coup. For regimes that have never experienced a coup attempt, an analogous measure would be the change in payoff-relevant measures since the first year of the regime.

The model also suggests that some empirical relationships may be different in the early stages of a regime than they are in more mature regimes. While technical results along these lines are not straightforward, one potential conclusion to draw from the model is that in general structural factors should be more straightforwardly associated with coup risk in the early stages of a regime, before the countervailing effect of demonstrating their strength by surviving tough times kicks in. Similarly, the model suggests that the coup risk in the early phases of a regime could be negatively associated with coup risk in the future. Future empirical work could examine this prediction by looking at how economic (and other) conditions at the time of past coups affects the likelihood of coups in the future.

None of these proposals address perhaps the most thorny empirical suggested by the model: that some variance in coup incidence is determined by whether societies play a "no coup" or "some coup" equilibrium. If societies consistently play the same equilibrium over time, then this problem could be alleviated by including fixed effects in an empirical model. While there is no technical reason why a society can not arbitrarily switch between the no coup and some coups equilibria, thinking outside the formal equilibrium concepts we typically use this seems implausible. More plausibly, crises may not increase the chances of a coup for reasons directly linked to how they affect the officers' incentives, but by providing a focal point that helps the officers coordinate on the equilibrium with the highest level of coup activity - in fact, such an equilibrium may be optimal if it unseats ineffective governments or gives sitting governments an incentive to manage the economy and other aspects of the political system more effectively. ${ }^{22}$

\footnotetext{
${ }^{22}$ Bueno De Mesquita (2010) studies a similar model that also has multiple equilibria, and makes a related observation important variation in revolutionary activity may be due to playing a different equilibrium rather than structural factors. See also Tamer (2003) and Angeletos and Pavan (2013) for further discussion
} 
This indeterminacy can also be interpreted in light of theories of civilian rule centered on legitimacy or professionalism (Huntington, 1957; Janowitz, 1960). While the critique that these are circular arguments is important, the multiplicity of equilibria in the model here follows from a somewhat circular logic as well. In one equilibrium, officers are pessimistic about the possibility of a coup because they think others will not stage a coup, and others will not stage a coup because they think others will not stage a coup, etc. In the equilibria with coups past period one, officers have a mutually reinforcing belief that coups are possible. Labeling the mutual belief that no one will stage a coup "professionalism" - I believe the other officers are professionals, and they think I am professional or deeming equilibria with coups "illegitimate" is thus consistent with the logic of the model.

\section{Conclusion}

The rarity of military rule and pervasiveness of civilian dominance over armed forces constitute one of the major puzzles in the study of politics. The model here augments a past argument for how this is possible - that divisions in the military create a coordination problem - with time and learning dynamics to provide a mechanism for sustained civilian rule. This does not explain the origin of civilian regimes, but it does provide an explanation for how civilian regimes avoid transitioning to military regimes.

Finally, an issue purposefully dodged thus far is what exactly a "regime" is. More precisely, the regime strength $\theta$ could be interpreted as a property of, among other things, an individual leader, a ruling party, a dynasty, or a period of democratic rule. In some of these interpretations - particularly individual leaders - there will often be new regimes by constitutional or other mechanisms, i.e., without military intervention. A natural way on the implications of equilibrium multiplicity for empirical analysis. 
to model this would be to have the strength of the current regime be a function of both the individual leader and the regime more broadly. So, new individual leadership - through democratic turnover, dynastic succession, or other means - will inherit some of the learned strength of the previous regime but with added uncertainty about leader-specific characteristics. While more formal analysis is beyond the scope here, a possible consequence would be that new leadership may induce some instability, but not as much as more dramatic regime change.

In addition, the group threatening to overthrow the regime need not be the military, but could be civilian elites or citizens more generally. So, while the primary interpretation of the model here was how civilian regimes can be insulated against attacks from the military, it can also provide insight into the stability of any regime - whether civilian and democratic or a repressive military autocracy - against potential overthrow. 


\section{References}

Acemoglu, Daron, Davide Ticchi and Andrea Vindigni. 2010. "A Theory of Military Dictatorships." American Economic Journal: Macroeconomics 2(1):1-42.

Aney, Madhav S. and Giovanni Ko. 2010. “Custodes invicem custodiunt: Commitment through competition by specialists in violence." Manuscript.

Angeletos, George-Marios and Alessandro Pavan. 2013. "Selection-free predictions in global games with endogenous information and multiple equilibria." Theoretical Economics 8(3):883-938.

URL: $h t t p: / / d x$. doi.org/10.3982/TE1156

Angeletos, George-Marios, Christian Hellwig and Alessandro Pavan. 2007. "Dynamic Global Games of Regime Change: Learning, Multiplicity, and Timing of Attacks." Econometrica 75(3):711-756.

Bearden, Milton. 2012. "Requiem for a Russian Spy." Foreign Policy July/August.

Belkin, Aaron and Evan Schofer. 2003. “Towards a Structural Understanding of Coup Risk." Journal of Conflict Resolution 47(5):594-620.

Besley, Timothy and James A. Robinson. 2009. “Quis Custodiet Ipsos Custodes? Civilian Control over the Military." Manuscript.

Bleck, Jaime and Kristin Michelitch. 2013. “Capturing the Airwaves, Capturing the Nation: Citizen Response to Putschist-controlled Radio." Manuscript.

Boix, Carles and Milan W Svolik. 2013. “The Foundations of Limited Authoritarian Government: Institutions, Commitment, and Power-Sharing in Dictatorships." The Journal of Politics 75(02):300-316. 
Bueno De Mesquita, Ethan. 2010. "Regime change and Revolutionary Entrepreneurs." American Political Science Review 108(3):446-466.

Carlsson, Hans and Eric Van Damme. 1993. "Global games and equilibrium selection." Econometrica 61:989-1018.

Casper, Brett A. and Scott A. Tyson. 2012. "Popular Uprisings and the Strategic Risk of Coup." American Political Science Association annual meeting paper.

Collier, Paul and Anke Hoeffler. 2004. "Greed and grievance in civil war." Oxford economic papers 56(4):563-595.

Debs, Alexandre. 2010. "Living by the Sword and Dying by the Sword? Leadership Transitions in and out of Dictatorships." Manuscript.

Decalo, Samuel. 1976. Coups and army rule in Africa: Studies in military style. Yale University Press New Haven.

Dewan, Torun and David P. Myatt. 2008. "The Qualities of Leadership: Direction, Communication, Obfuscation." American Political Science Review 102(3):351-368.

Feaver, Peter D. 1996. “The Civil-Military Problematique: Huntington, Janowitz, and the Question of Civilian Control." Armed Forces and Society 23(2):149-178.

Finer, Samuel E. 1962. The Man on Horseback: The Role of the Military in Politics. Pall Mall Press.

Geddes, Barbara. 1999. "What do we know about Democratization after Twenty Years." Annual Review of Political Science 2:115-44.

Geddes, Barbara, Joseph Wright and Erica Frantz. 2013. “New Data Set: Autocratic Breakdown and Regime Transitions." Manuscript. 
Geletovic, Alexander and Ricardo Sanhueza. 2000. "Citizens, autocrats, and plotters: A model and new evidence on coups D'etat." Economics and Politics 12(2):183-204.

Goemans, Hein and Nikolay Marinov. 2013. "Coups and Democracy." British Journal of Political Science Forthcoming.

Huntington, Samuel P. 1957. The Soldier and the State: The Theory of Politics and Civil-Military Relations. Harvard University Press.

Janowitz, Morris. 1960. The Professional Soldier : A Social and Political Portrait. New York: Free Press.

Kim, Nam Kyu. 2014. "Revisiting Economic Shocks and Coups." Forthcoming, Journal of Conflict Resolution .

Kricheli, Ruth, Yair Livne and Beatriz Magaloni. 2011. "Taking to the Streets: Theory and Evidence on Protests under Authoritarianism." Manuscript.

Little, Andrew T. 2012. "Elections, Fraud, and Election Monitoring in the Shadow of Revolution." Quarterly Journal of Political Science 7(3):249-283.

Londregan, John B. and Keith T. Poole. 1990. “Poverty, The Coup Trap, and the Seizure of Executive Power." World Politics 42(2):151-183.

Luttwak, Edward. 1968. Coup d'Etat: A practical handbook. Allen Lane.

Marcano, Christina and Alberto Barrera Tyszka. 2007. Hugo Chavez. Random House Digital Inc.

Morris, Stephen and Hyun Song Shin. 2003. Global Games: Theory and Applications. In Advances in Economics and Econometrics (Proceedings of the Eighth World Congress of 
the Econometric Society), ed. Mathias Dewatripont, Lars Peter Hansen and Stephen J. Turnovsky. Number 37 Cambridge Univ. Press.

Powell, Jonathan. 2012. "Determinants of the Attempting and Outcome of Coups d'état." Journal of Conflict Resolution 56(6):1017-1040.

Powell, Jonathan M. and Clayton L. Thyne. 2011. “Global Instances of Coups from 1950Present." Journal of Peace Research Forthcoming.

Przeworski, Adam. 1996. Some Problems in the Study of Transition to Democracy. In Transitions from Authoritarian Rule: Comparative Perspectives, ed. Guillermo O'Donnell, Philippe C. Schmitter and Laurence Whitehead.

Przeworski, Adam. 2012. “Elections and Coups, Coups and Elections.” Manuscript.

Rivero, Gonzalo. 2010. “Military Governments and Military Coups.” Manuscript.

Seale, Patrick. 1991. Asad: Between Institutions and Autocracy. SUNY series in Middle Eastern Studies.

Shadmehr, Mehdi and Dan Bernhardt. 2011. "Collective Action with Uncertain Payoffs: Coordination, Public Signals and Punishment Dilemmas." American Political Science Review 105(4):829 - 851.

Singh, Naunihal. 2014. Seizing Power: The Strategic Logic of Military Coups. Johns Hopkins University Press.

Smith, Benjamin. 2005. "Life of the Party: The Origins of Regime Breakdown and Persistence under Single-Party Rule." World Politics 57(3):421-451.

Svolik, Milan W. 2009. "Power Sharing and Leadership Dynamics in Authoritarian Regimes." American Journal of Political Science 53(2):477-494. 
Svolik, Milan W. 2013. “Contracting on Violence: The Moral Hazard in Authoritarian Repression and Military Intervention in Politics." Journal of Conflict Resolution 57(5):765794.

Tamer, Elie. 2003. “Incomplete simultaneous discrete response model with multiple equilibria." The Review of Economic Studies 70(1):147-165.

Tyson, Scott and Alastair Smith. 2013. "Regime Insiders and Revolutions." Midwest Political Science Association Annual Meeting Paper.

Wright, Joseph, Erica Frantz and Barbara Geddes. 2013. “Oil and Autocratic Regime Survival." Forthcoming, British Journal of Political Science.

Zuk, Gary and William R. Thompson. 1982. "The Post-Coup Military Spending Question: A Pooled Cross-Sectional Time Series Analysis." American Political Science Review 76(1):60-74. 


\section{Appendix}

\section{Equilibrium Condition}

The equilibrium conditions for the model are:

1. (Symmetry) All officers use the same strategy

2. (Monotonicity) Officer strategies in each period are monotone in their private signal, i.e., they either (1) choose $a_{i t}=1$ if and only if $s_{i}<\hat{s}_{t}(\cdot)$, (2) always join the coup (write this $\left.\hat{s}_{t}=-\infty\right)$, or (3) never join the coop $\left(\hat{s}_{t}=\infty\right)$.

3. (Optimality) Officers choose $a_{i t}=1$ if and only if this gives a higher expected payoff than $a_{i t}=0$ given the other officers use $\hat{s}_{t}$ and their belief about $\theta$.

4. (Consistency) Beliefs about $\theta$ are derived by Bayes' rule when possible given the private signals and whether a coup has succeed in past periods.

Write the always coup and never coup strategies $\hat{s}_{t}=\infty$ and $\hat{s}_{t}=-\infty$, respectively.

Since the officers do not observe past coup sizes, and the game ends if there is a coup before period $t$, the only part of a history that officers can condition on is their private signal. Combining this observation with the symmetry and monotonicity conditions, we can describe the entire officer strategy is a sequence $\left(\hat{s}_{1}, \hat{s}_{2}, \ldots\right)$ of thresholds such that the officer rebels in period $t$ if and only if $s_{i}<\hat{s}_{t}$.

To formally describe the payoffs, let $R_{t}=0$ if the regime has not fallen by time $t$, and $R_{t}=1$ if there is a successful coup in any period $\{1, \ldots, t-1\}$. The period payoffs are:

$$
u_{i t}= \begin{cases}-R_{t+1} k_{0 t}+\left(1-R_{t+1}\right) v_{0 t} & a_{i t}=0 \\ R_{t+1} v_{1 t}-\left(1-R_{t+1}\right) k_{1 t} & a_{i t}=1\end{cases}
$$


Let $\rho \in(0,1)$ be a common discount rate, and officer $i$ 's payoff for the entire game be:

$$
U_{i}=\sum_{t=1}^{\infty} \rho^{t-1}\left(1-R_{t}\right) u_{i t}
$$

\section{Period 1 Equilibrium Condition}

In the first period, officers only condition their action on their private signal $s_{i}$ and the period coup favorability $q_{1}$. Since the private signals are normally distributed with mean $\theta$ and precision $\eta$, given a proposed period 1 cutoff strategy strategy $\hat{s}_{1}$, the proportion of officers choosing to participate in a coup as a function of the true regime strength $\theta$ is:

$$
A_{1}(\theta)=\operatorname{Pr}\left(s_{i}<\hat{s}_{1} \mid \theta\right)=\Phi\left(\sqrt{\eta}\left(\hat{s}_{1}-\theta\right)\right)
$$

where $\Phi$ is the cumulative density function of the standard normal distribution. Given this strategy, there is a successful coup in the first period if and only if $\theta<\hat{\theta}_{1}$ where $\hat{\theta}_{1} \in(0,1)$ solves $A\left(\hat{\theta}_{1}\right)=\hat{\theta}_{1}$, or:

$$
\Phi\left(\sqrt{\eta}\left(\hat{s}_{1}-\hat{\theta}_{1}\right)\right)=\hat{\theta}_{1}
$$

The left-hand side of this equation is decreasing with range $(0,1)$, so there is a unique $\hat{\theta}_{1} \in(0,1)$ solving equation 4 .

For $\hat{s}_{1}$ to be an equilibrium strategy, Optimality requires that an officer observing exactly $s_{i}=\hat{s}_{1}$ is indifferent between joining the coup or not, or $q_{1}=\operatorname{Pr}\left(\theta<\hat{\theta}_{1} \mid s_{i}\right)$. Consistency requires this belief is formed by Bayes' rule.

By standard rules of Bayesian updating, an officer observing signal $s_{i}$ 's belief about $\theta$ is normally distributed with mean $\frac{\alpha}{\alpha+\eta} \mu_{0}+\frac{\eta}{\alpha+\eta} s_{i}$ and precision $\alpha+\eta$. So, an equilibrium 
$\hat{\theta}_{1}$ solves:

$$
q_{1}=\operatorname{Pr}\left(\theta<\hat{\theta}_{1} \mid s_{i}=\hat{s}_{1}\right)=\Phi\left(\sqrt{\alpha+\eta}\left(\hat{\theta}_{1}-\left(\frac{\alpha}{\alpha+\eta} \mu_{0}+\frac{\eta}{\alpha+\eta} \hat{s}_{1}\right)\right)\right)
$$

Rearranging equation 4 gives $\hat{s}_{1}=(1 / \sqrt{\eta}) \Phi^{-1}\left(\hat{\theta}_{1}\right)+\hat{\theta}_{1}$, and combining this with the above and simplifying gives an equilibrium condition for $\hat{\theta}_{1}$ in the main text. An equilibrium $\hat{\theta}_{1}$ solves equation 2 , which uniquely determines the equilibrium threshold rule $\hat{s}_{1}$. Whether one or more than one pair $\left(\hat{\theta}_{1}, \hat{s}_{1}\right)$ meets this conditions is a common result (e.g., Morris and Shin (2003)). A more formal statement of proposition 1 is:

Lemma 7. In the first period, a coup occurs, though it may fail. Further:

i) There is a unique equilibrium for all $q_{1}$ if and only if $\eta \geq \alpha^{2} /(2 \pi)$, and

ii) if there is a unique equilibrium, the expected proportion of coup participants and probability of a successful coup are decreasing in $k_{11}, v_{01}$ and $\mu_{0}$, and increasing in $k_{01}$ and $v_{11}$.

Proof The derivative of the right-hand side of the equilibrium condition with respect to $\hat{\theta}_{1}$ equal to a positive constant times:

$$
\left(\frac{\alpha}{\sqrt{\alpha+\eta}}-\frac{\sqrt{\eta}}{\sqrt{\alpha+\eta}}\left(1 / \phi\left(\Phi^{-1}\left(\hat{\theta}_{1}\right)\right)\right)\right)
$$

(The derivative of $\Phi^{-1}\left(\hat{\theta}_{1}\right)$ is $1 / \phi\left(\Phi^{-1}\left(\hat{\theta}_{1}\right)\right)$ ). The minimum value of $1 / \phi\left(\Phi^{-1}\left(\hat{\theta}_{1}\right)\right)$ is $\sqrt{2 \pi}$, so this term is always decreasing if and only if

$$
\begin{array}{r}
\frac{\sqrt{\eta} \sqrt{2 \pi}}{\sqrt{\alpha+\eta}} \geq \frac{\alpha}{\sqrt{\alpha+\eta}} \\
\eta \geq \alpha^{2} /(2 \pi)
\end{array}
$$

If this condition holds and the hence the right-hand side of equation 2 is always decreasing. Further, the right-hand side of equation 2 approaches 1 as $\hat{\theta} \rightarrow 0$ and 0 as $\hat{\theta} \rightarrow 1$. Since 
$q_{1} \in(0,1)$, there will be a unique $\hat{\theta}_{1}$ solving the condition and hence a unique equilibrium by the Intermediate Value Theorem. If $\eta<\alpha^{2} /(2 \pi)$, there will be some interval of $\hat{\theta}_{1}$ such that $\operatorname{Pr}\left(\theta<\hat{\theta}_{1} \mid s_{i}=\hat{s}_{1}\right)$ is increasing, so there exists a $q \in(0,1)$ in the range of $\operatorname{Pr}\left(\theta<\hat{\theta}_{1} \mid s_{i}=\hat{s}_{1}\right)$ such that if $q_{1}=q$ there will be three intersections, ensuring multiple equilibria.

For the comparative statics, implicitly differentiating the equilibrium condition gives $\frac{\partial \hat{\theta}_{1}}{\partial \mu_{0}}>0$, which implies $\frac{\partial \hat{s}_{1}}{\partial \mu_{0}}>0$, hence the proportion of participants and the probability of a successful coup are decreasing in $\mu_{0}$. Similarly $\frac{\partial \hat{\theta}_{1}}{\partial q_{1}}>0$, which implies $\frac{\partial \hat{s}_{1}}{\partial q_{1}}>0$. Differentiating $q_{1}$ with respect to the primitive payoff parameters implies $\frac{\partial q_{1}}{\partial v_{01}}>0, \frac{\partial q_{1}}{\partial k_{11}}>0$, $\frac{\partial q_{1}}{\partial k_{01}}<0$, and $\frac{\partial q_{1}}{\partial v_{11}}<0$, giving the desired results.

\section{Periods $t \geq 2$}

In periods $t \geq 2$ the officers have the additional information that $\theta>\hat{\theta}_{t-1}$, and hence their belief about $\theta$ follows a truncated normal distribution with location parameter $\frac{\alpha}{\alpha+\eta} \mu_{0}+$ $\frac{\eta}{\alpha+\eta} s_{i} \equiv \bar{\mu}\left(s_{i}\right)$ and scale parameter $\alpha+\eta$, truncated from below at $\hat{\theta}_{t-1}$. So the cdf of the belief about $\theta$ is:

$$
\operatorname{Pr}(\theta<x)= \begin{cases}0 & x \leq \hat{\theta}_{t-1} \\ 1-\frac{\Phi\left(\sqrt{+\alpha}\left(\bar{\mu}\left(s_{i}\right)-x\right)\right)}{\Phi\left(\sqrt{\eta+\alpha}\left(\bar{\mu}\left(s_{i}\right)-\hat{\theta}_{t-1}\right)\right)} & x>\hat{\theta}_{t-1}\end{cases}
$$

\section{Proof of proposition 2}

As in the main text restrict attention to symmetric monotone equilibria, where officer $i$ rebels in time period $t$ if and only if $s_{i}<\hat{s}_{t}$ for some $\hat{s}_{t} \in \mathbb{R} \cup\{-\infty, \infty\}$, where $\hat{s}_{t}=-\infty$ means not rebelling for any signal and $\hat{s}_{t}=\infty$ means joining the coup no matter what. Since the regime surviving until period $t$ implies it must have survived up to all $t^{\prime}<t$, $\left\{\hat{\theta}_{t}\right\}$ must be a nondecreasing sequence on $(0,1)$. 
Suppose there is an equilibrium where $\hat{\theta}_{1}$ and $\hat{s}_{1}$ are defined as above and for $t \geq 2$ $\hat{s}_{t}=-\infty$ and $\hat{\theta}_{t}=\hat{\theta}_{1}$. Given $\hat{\theta}_{t}=\hat{\theta}_{1}$ officers assign $\operatorname{Pr}\left(\theta<\hat{\theta}_{t} \mid \theta \geq \hat{\theta}_{t-1}, s_{i}\right)=0$ for any $s_{i}$. Hence it is optimal to never join the coup, i.e., $\hat{s}_{t}=-\infty$.

\section{Derivation of equation 3}

In a proposed equilibrium where there is a successful coup in period $t \geq 2$ if and only if $\theta<\hat{\theta}_{t}$, the probability of the coup succeeding from the perspective of an officer observing the proposed cutoff signal is:

$$
\operatorname{Pr}\left(\theta<\hat{\theta}_{t} \mid \hat{\theta}_{t-1}, s_{i}=\hat{s}_{t}\right)= \begin{cases}0 & \hat{\theta}_{t} \leq \hat{\theta}_{t-1} \\ 1-\frac{\Phi\left(\sqrt{\eta+\alpha}\left(\mu_{t}\left(\hat{s}_{t}\right)-\hat{\theta}_{t}\right)\right)}{\Phi\left(\sqrt{\eta+\alpha}\left(\mu_{t}\left(\hat{s}_{t}\right)-\hat{\theta}_{t-1}\right)\right)} & \hat{\theta}_{t}>\hat{\theta}_{t-1}\end{cases}
$$

As in period 1, for a fixed strategy $\hat{s}_{t}$ the critical $\hat{\theta}_{t}$ that determines whether the regime survives solves:

$$
\hat{\theta}_{t}=\Phi\left(\sqrt{\eta}\left(\hat{s}_{t}\right)-\hat{\theta}_{t}\right)
$$

hence $\hat{s}_{t}=\hat{\theta}_{t}+\Phi^{-1}\left(\hat{\theta}_{t}\right) \sqrt{\eta}$. So, the equilibrium condition for there to be a coup attempt in period $t$ given $\hat{\theta}_{t-1}$ is that there exists a $\hat{\theta}_{t} \in\left(\hat{\theta}_{t-1}, 1\right)$ that solves:

$$
\begin{aligned}
q_{t} & =1-\frac{\Phi\left(\sqrt{\eta+\alpha}\left(\mu_{t}\left(\hat{s}_{t}\right)-\hat{\theta}_{t}\right)\right)}{\Phi\left(\sqrt{\eta+\alpha}\left(\mu_{t}\left(\hat{s}_{t}\right)-\hat{\theta}_{t-1}\right)\right)} \\
& =1-\frac{\Phi\left(\frac{\sqrt{\eta}}{\sqrt{\eta+\alpha}}\left(\Phi^{-1}\left(\hat{\theta}_{t}\right)+\frac{\alpha}{\sqrt{\beta}}\left(\mu_{0}-\hat{\theta}_{t}\right)\right)\right.}{\Phi\left(\frac{\sqrt{\eta}}{\sqrt{\eta+\alpha}}\left(\Phi^{-1}\left(\hat{\theta}_{t}\right)+\frac{\alpha}{\sqrt{\beta}}\left(\mu_{0}-\hat{\theta}_{t}\right)\right)+\sqrt{\eta+\alpha}\left(\hat{\theta}_{t}-\hat{\theta}_{t-1}\right)\right)} \equiv p^{*}\left(\hat{\theta}_{t}, \hat{\theta}_{t-1}\right)
\end{aligned}
$$




\section{Proof of Proposition 3}

Whether there is a $\hat{\theta}_{t}$ solving this equation depends on the nature of the $p^{*}(\cdot)$ function. First, note that $p^{*}(\cdot)$ is continuous in all arguments. Second, $p^{*}$ is strictly positive for $\hat{\theta}_{t} \in$ $\left(\hat{\theta}_{t-1}, 1\right)$. So, when the maximal value of $p^{*}$ with respect to $\hat{\theta}_{t}$ is greater than $q_{t}$, there will exist at least one potential equilibrium. If not, the only equilibrium strategy for period $t$ will be for there to be no coup. So, there is an equilibrium with a coup if and only if $q_{t} \leq \max _{\theta_{t}} p^{*}\left(\hat{\theta}_{t}, \hat{\theta}_{t-1}\right) \equiv \tilde{q}_{t}$

\section{Proof of Proposition 4}

This follows from the fact that $p^{*}$ is decreasing in $\hat{\theta}_{t-1}$, and hence the maximal value of $p^{*}$ (i.e., $\tilde{q}_{t}$ ) must be decreasing in $\hat{\theta}_{t-1}$.

\section{Proof of lemma 5}

The past regime strengths $\theta_{1}, \ldots, \theta_{t-1}$ are all normally distributed with mean $\bar{\theta}$ and precision $\tau_{\epsilon}$, so by standard rules of Bayesian updating the officer's belief about $\bar{\theta}$ is normally distributed with mean $\frac{\sum_{j=1}^{r-1} \tau_{\epsilon} \theta^{j}+\tau_{0} \mu^{1}}{\tau_{0}+(r-1) \tau_{\epsilon}}$ and precision $\tau_{0}+(r-1) \tau_{\epsilon}$. So the belief about $\theta^{r}$, which is equal to $\theta^{r}$ plus a normal random variable with mean 0 and precision $\tau_{\epsilon}$, is normally distributed with the mean and precision in the main text.

\section{Trajectories Model}

The changes to the information structure are all described in the main text, and the solution concept is the same as in the baseline. The period payoffs in the trajectories model are are: 


\begin{tabular}{|r|c|c|}
\hline & Coup Fails $\left(A_{t}<\theta^{r}\right)$ & Coup Succeeds $\left(A_{t} \geq \theta^{r}\right)$ \\
\hline Support Government $\left(a_{i t}=0\right)$ & $v_{0 t}$ & $-k_{0 t}$ \\
\hline Join Coup $\left(a_{i t}=1\right)$ & $-k_{1 t}$ & $v_{1 t}$ \\
\hline
\end{tabular}

Let $\rho \in(0,1)$ be a common discount rate, and officer $i^{\prime}$ 's payoff for the entire game be:

$$
U_{i}=\sum_{t=1}^{\infty} \rho^{t-1} u_{i t}
$$

Let $t_{0}^{r}$ be the period that regime $r$ begins (if at all), and $s_{i}^{r}$ be the private signal observed about regime $r$.

The equilibrium conditions for the initial period of each regime are the same as above with $\alpha^{r}$ replacing $\alpha$ and a shift in the time index, giving:

$$
q_{t_{0}^{r}}=\Phi\left(\frac{\alpha^{r}}{\sqrt{\alpha^{r}+\eta}}\left(\hat{\theta}_{t_{0}^{r}}^{r}-\mu^{0}\right)-\frac{\sqrt{\eta}}{\sqrt{\alpha^{r}+\eta}} \Phi^{-1}\left(\hat{\theta}_{t_{0}^{r}}^{r}\right)\right)
$$

As above, I only consider the case where there is a unique equilibrium for the first period of each regime, which can be assured by $\tau_{\epsilon}<\sqrt{\eta /(2 \pi) .}{ }^{23}$

Also analogously to the baseline model, the belief about $\theta$ in period $t>t_{0}^{r}$ if regime $r$ is in power is truncated normal with distribution:

$$
\operatorname{Pr}(\theta<x)= \begin{cases}0 & x \leq \hat{\theta}_{t^{\prime}-1}^{r} \\ 1-\frac{\Phi\left(\sqrt{\eta+\alpha^{r}}\left(\bar{\mu}\left(s_{s}^{r}\right)-x\right)\right)}{\Phi\left(\sqrt{\eta+\alpha^{r}}\left(\bar{\mu}\left(s_{i}^{r}\right)-\hat{\theta}_{t-1}^{r}\right)\right)} & x>\hat{\theta}_{t-1}^{r}\end{cases}
$$

giving the equilibrium condition for periods $t>t_{0}^{r}$ under regime $r$ :

\footnotetext{
${ }^{23}$ This follows from the the fact that $\alpha^{r}<\tau_{\epsilon}$ and the inequality derived in proposition 1.
} 


$$
q_{t}=1-\frac{\Phi\left(\frac{\sqrt{\eta}}{\sqrt{\eta+\alpha^{r}}}\left(\Phi^{-1}\left(\hat{\theta}_{t}\right)+\frac{\alpha}{\sqrt{\beta}}\left(\mu_{0}^{r}-\hat{\theta}_{t}\right)\right)\right.}{\Phi\left(\frac{\sqrt{\eta}}{\sqrt{\eta+\alpha}}\left(\Phi^{-1}\left(\hat{\theta}_{t}\right)+\frac{\alpha}{\sqrt{\beta}}\left(\mu_{0}-\hat{\theta}_{t}\right)\right)+\sqrt{\eta+\alpha}\left(\hat{\theta}_{t}-\hat{\theta}_{t-1}\right)\right)}
$$

\section{Proof of proposition 6}

The existence of a coup follows from the fact that the belief about the new regime is a non-truncated normal, and the analysis of the baseline model. The second part follows from the fact that $\mu^{r}$ is increasing in $\theta^{i}$ for $i=1, \ldots, r-1$. 